\title{
Advances in Delivery Systems for Doxorubicin
}

\section{Na Zhao', Martin C Woodle ${ }^{2}$ and A. James Mixson ${ }^{1 *}$}

${ }^{1}$ Department of Pathology, University of Maryland School of Medicine, Baltimore, Maryland 21201, USA

${ }^{2}$ Aparna Biosciences Corp, 9119 Gaither Rd, Gaithersburg, MD 20877, USA

\begin{abstract}
Doxorubicin is a widely used chemotherapy agent. Despite its utility, several adverse side effects, especially its irreversible cardiotoxicity and reversible nephrotoxicity, have prompted the development of liposomal carriers, many of which are FDA approved. Antitumor efficacies of approved liposome-Dox preparations can equal or exceed that of conventional doxorubicin. Because these liposomes carriers accumulate in solid tumor tissues via an enhanced permeation and retention (EPR) effect, these carriers have an improved safety profile. Nevertheless, a significant problem with the current drug delivery preparations of doxorubicin is a lack of efficacy toward tumors that exhibit multidrug resistance. In this review, we consider the development of drug delivery systems for doxorubicin, which improve the therapeutic window (efficacy and safety) and which address limitations of the current FDA-approved doxorubicin formulations.
\end{abstract}

Keywords: Doxorubicin; Nanoparticle; Systemic; Intratumoral; Multidrug resistance

\section{Introduction}

Doxorubicin (Dox) alone or in combination with other chemotherapy is a common first line therapy for numerous cancers including breast, ovarian, bladder, and lung (Figure 1). Although the mechanism of action for Dox is still being studied, proposed mechanisms include intercalation into DNA disrupting gene expression, generation of reactive oxygen species, and inhibition of topoisomerase II, a gyrase important for DNA synthesis and replication [1]. Most recently, Denard et al. found that Dox increased intracellular ceramide levels, resulting in release of a membrane transcription factor, CREB3L1 [2]. CREB3L1 affects expression of multiple genes, one of which is the tumor suppressor, p21. Notably, tumor cells with an elevated level of CREB3L are sensitive to doxorubicin, whereas those with low levels are resistant [3].

Regardless of whether one or several of these proposed mechanisms are in play, Dox has cell-cycle specific activity. In addition to causing $\mathrm{G} 0 / \mathrm{S}$ and G2/M arrest, it also increases oxygen radicals resulting in apoptosis. Dox has p53 dependent and independent mechanisms. Notably, the delivery method may influence the pathway activated by Dox. For example, bolus injection resulted in significant apoptosis of treated cells associated with G2 arrest, phosphorylation of p53,<smiles>COc1cccc2c1C(=O)c1c(O)c3c(c(O)c1C2=O)C[C@@](O)(C(=O)CO)C[C@@H]3O[C@H]1C[C@H](N)[C@@H](O)[C@@H](C)O1</smiles>

Figure 1: Structural formula of doxorubicin and increased levels of BAX and p21 [4]. In contrast, cells exposed to constant levels of Dox showed decreased cell number yet little apoptosis.

The most serious long-term adverse effect of Dox therapy is irreversible cardiomyopathy, which is based on the total cumulative dose. In one clinical study, 4\% of patients receiving dosages of 500-550 $\mathrm{mg} / \mathrm{m}^{2}$ developed congestive heart failure, $18 \%$ with dosages of $551-600$ $\mathrm{mg} / \mathrm{m}^{2}$, and $36 \%$ with cumulative dosages higher than $601 \mathrm{mg} / \mathrm{m}^{2}$ [5]. Increased levels of reactive oxygen species resulting in apoptosis in the heart appear to have a significant role in Dox cardiomyopathy. Efforts to mitigate Dox cardiomyopathy and other adverse effects have been undertaken via liposomal drug delivery [6,7].

\section{FDA-Approved Liposomal-Doxorubicin Preparations}

Several systemically administered liposomal Dox have been investigated and approved including pegylated (Doxil ${ }^{\circ}$, Lipodox $\left.^{\star}\right)$ and unpegylated (Myocet) forms. These liposomes incorporate Dox into an aqueous core. As for efficacy, general consensus has not been reached that these liposome preparations increase survival in breast cancer patients with one notable exception [8]. In cancer patients who have a high risk of cardiac disease (i.e., cardiomyopathy or MI), pegylated liposomal doxorubicin (PLD) does increase survival compared to conventional Dox. Importantly, there is a better safety profile with liposomal Dox formulations. Compared to patients treated with conventional Dox, patients treated with liposomal-Dox exhibit less cardiotoxicity, nausea and vomiting, as well as less myelosuppression $[1,9]$. Fewer side effects by the liposome preparations are likely due to greater accumulation of liposomal-Dox (i.e., Doxil ${ }^{\circ}$ ) in tumor tissue (and lesser amounts in other tissues) through an enhanced retention and permeability (EPR) effect. Based on increased leakiness of tumor

*Corresponding author: A. James Mixson, Department of Pathology, University of Maryland School of Medicine, Baltimore, Maryland 21201, USA, Tel: 4107063223; E-mail: JMixson@som.umaryland.edu

Received: October 25, 2018; Accepted: November 01, 2018; Published: November 04, 2018

Citation: Zhao N, Woodle MC, Mixson AJ (2018) Advances in Delivery Systems for Doxorubicin. J Nanomed Nanotechnol 9: 519. doi: 10.4172/2157-7439.1000519

Copyright: (c) 2018 Zhao N, et al. This is an open-access article distributed unde the terms of the Creative Commons Attribution License, which permits unrestricted use, distribution, and reproduction in any medium, provided the original author and source are credited. 
blood vessels and reduced lymphatics, EPR enables passive targeting of liposomes to tumors compared to other tissues. Nanoparticles (NP), including liposomes between 10 and $200 \mathrm{~nm}$, are dependent on EPR for their accumulation in tumors.

\section{Pre-clinial Delivery Platforms of Dox}

Despite an enhanced efficacy and safety profile of the clinicallyapproved liposome carriers, efforts have continued to develop Dox carriers with further improved efficacy and safety. Whereas some liposomal forms of Dox are FDA-approved, none of the non-liposomal drug delivery forms have received regulatory approval. Similar to the liposome forms, non-liposomal Dox products are dependent on the EPR effect. In this review, we will focus on carriers of Dox in preclinical trials. First, we will examine carriers that have been developed to improve accumulation of Dox in tumors. Second, we will review Dox carriers, which also incorporate inhibitory agents that reverse the resistance of tumor cells to Dox. Dox resistance by tumors is often mediated by multidrug resistance enhancing the cellular efflux of Dox. Third, since several carriers have utilized DNA to bind to Dox, we will discuss this form of delivery separately. Several base pairs in DNA, in particular GC base pairs, have a high affinity for Dox. Whereas the above-mentioned sections discuss carriers designed to be systemically delivered, the final section discusses progress to improve local delivery of Dox.

\section{Nanoparticle Dox Drug Delivery}

Diverse types of nanoparticle (NP) drug carriers have been developed and tested for systemic delivery and release of Dox at the tumor site. We will examine the NP carriers by class in this section covering polymeric NPs and conjugates, micelles, exosomes, and paramagnetic NPs, to improve delivery of Dox in tumors.

\section{Polymeric NPs and conjugates}

Chitosan is a linear biodegradable polysaccharide in which NPs have been formulated to deliver chemotherapy [10-14] and nucleic acids $[15,16]$. In an early study, the group of Maitra incorporated a dextran-Dox conjugate into a chitosan nanoparticle [10]. They compared conventional "free" Dox, the dextran conjugate alone, and the chitosan-dextran conjugate NP groups for reducing tumor size (subcutaneously implanted J774A.1 macrophage tumor) and prolonging survival in Balb/c mice. Treatment was initiated when the tumor size was about $200 \mathrm{~mm}^{3}$ and 4 weekly intravenous dosages were administered. The NP group $(16 \mathrm{mg} / \mathrm{kg} / \mathrm{dose})$ was the most effective with about a 50\% regression in tumor size at day 90 compared to a maximum size at day 45 . Moreover, the group treated with the nanoparticle had prolonged survival with $50 \%$ of the mice alive at day 90. In contrast, all mice in the free Dox group died by day 60 and only $25 \%$ of mice in the dextran-conjugate group survived by day 90 [10]. Similarly, a recent study found that Dox-loaded chitosan NP markedly inhibited tumor growth and prolonged survival of mice compared to free Dox [14]. Notably, in both studies, there was little to no evidence of toxicity observed in mice that received the Dox-loaded chitosan NPs.

In one of the few reports comparing efficacy of their NP with Doxil, Lee et al. demonstrated that a single dose of dendrimer-Dox conjugate cured mice with subcutaneously implanted colon cancer [17]. Notably, the C-26 colon carcinoma cells are resistant to Dox. The $8 \mathrm{~nm}$ carrier was comprised of a polyester dendrimer-PEG conjugate with a topologically globular structure. As a result of this structure, the covalently-bound doxorubicin was thought to be primarily located within the interior of the globular NP. The dendrimer-Dox carrier had a half-life in excess of $24 \mathrm{~h}$, enabling EPR to be more effective. A pHsensitive hydrazone linkage enabled Dox to be released in the acidic environment of the tumor and/or endosomes within tumor cells. At the maximal tolerated dose of the conjugate $(20 \mathrm{mg} / \mathrm{kg})$, survival of the tumor-bearing mice was $100 \%$. Similar results were found with Doxil but with only $90 \%$ of the mice surviving. The most effective results observed were at day 8 after implantation. It was reasoned that lower activity at earlier times was due to insufficient tumor vasculature, whereas at later times, the tumor was too large for effective treatment. Although these in vivo results were similar between the two treatment groups, the weight loss was significantly less in the conjugate treated group. The authors pointed out that a potential advantage of the dendrimer-conjugate carrier compared to Doxil $^{\oplus}$ was that a variety of drugs could be attached. In addition to polymer-conjugates, there are peptide-Dox conjugates (i.e., cell-penetrating peptides) that have shown marked inhibition of tumor cells in vitro [18]. These cellpenetrating peptide-conjugates were particularly effective against a Dox-resistant neuroblastoma cell line.

An alternative effort targeted liver cancer with a Dox-loaded polymeric NP [19]. The NPs were decorated with the polysaccharide ligands, pullalan (Pul) and/or arabipogalactan (AGn). Both ligands target asialoglycoprotein receptors, which are abundant on hepatocytes and liver cancer cells. In vitro studies showed that the ligand-targeted NPs have high uptake into a liver cancer cell line, HepG2, compared to non-targeted NPs. Moreover, elevated concentrations of the galactose, a sugar with high affinity for the same asialoglycoprotein receptor, reduced uptake of ligand targeted (Pul, AGn, and Pul/AGn) NPs, whereas galactose had no effect on uptake of untargeted NPs. Of the NPs tested, the Pul-NP-Dox showed the greatest inhibition of primary human liver tumors that had been implanted subcutaneously. Compared to the untreated group, the Pul-NP-Dox treatment gave about $75 \%$ reduction in tumor growth. Concomitant with greater tumor inhibition, tumor necrosis was greatest in the Pul-NP group. With marked reduction in the tumor collagen levels in the Pul-NP group, the authors speculated that greater tumor penetration of the particles occurred. Whereas the Pul-NP-Dox showed little to no toxicity to the mice, the conventional Dox alone demonstrated significant cardiotoxicity and renal toxicity.

Another group incorporated Dox into pegylated carboraneconjugated amphiphilic copolymer nanoparticles (PLMB-Dox) and studied efficacy toward U14 cervical cancer allografts [20]. The strategy combined delivering Dox to tumors in vivo with boron neutron capture therapy (BNCT). The addition of carboranes markedly increased the encapsulation of Dox in the NP through hydrogen-bonding. A second advantage of the carborane was its use of BNCT. Upon thermal neutron irradiation, the non-radioactive carboranes in the NPs yielded two high energy particles, which are cytotoxic to the tumor cells. Once subcutaneous tumors reached 60 to $90 \mathrm{~mm}^{3}$, the mice were injected on consecutive days with Dox $(10 \mathrm{mg} / \mathrm{kg})$ or PCMB-Dox NPs $(10 \mathrm{mg} /$ $\mathrm{kg}$ of Dox), and in both cases with and without radiation. At the end of the study (day 27), the most effective treatment was the PCMB-Dox NPs plus radiation, showing greater than $90 \%$ inhibition compared to the saline control group. PCMB-Dox NP suppressed tumor growth by about $80 \%$ whereas conventional Dox alone reduced tumors by only about $30 \%$. Notably, no toxic effects were observed in the PCMB-Dox as evidenced by histology, blood chemistries, and body weight.

\section{Micelles}

Studies combining both curcumin and Dox within a NP micelle showed synergy of their antitumor activity [21]. The NP micelles were 
comprised of a PEG-Dox conjugate formed by a $\mathrm{pH}$-sensitive Schiff's base. Furthermore, curcumin was incorporated within the micelle through a hydrophobic interaction with the PEG-Dox conjugate. These NPs were spherical in shape and approximately $180 \mathrm{~nm}$ in size. In vitro assays demonstrated that approximately $90 \%$ of the Dox was released in 48 hours at $\mathrm{pH}$ 5.0, whereas only about $10 \%$ was released at 48 hours at $\mathrm{pH}$ 7.4. In a mouse model with HepG2 tumors, pharmacokinetic studies demonstrated increased levels of Dox and curcumin in tumors compared to the free drugs. Consistent with these findings, the NP containing both Dox and curcumin had a greater antitumor effect compared to the combined free drug treatments or the NP containing only Dox. The NP-Dox-Curcumin inhibited tumor size by nearly $70 \%$ compared to untreated group, whereas the Dox/curcumin mixture and the NP-Dox groups inhibited tumor size by only about $40 \%$. Concomitant with greater tumor inhibition, the NP-Dox-Curcumin group showed significantly greater tumor necrosis compared to the other treatment groups.

A polyionic complex micelle was developed to co-deliver plasmids and Dox to tumor cells in vitro [22]. A blocked polymer of TAT, PEG, and PEI was complexed with plasmid DNA to form the polyionic micelle $\mathrm{NP}$. The Dox was conjugated to PEI via a $\mathrm{pH}$-sensitive hydrazine bond. Unlike studies discussed later, doxorubicin in this preparation does not intercalate into the DNA. The cytotoxicity and dose-response of this conjugate of Dox with the block TAT-PEG-PEI polymer was compared to free Dox. The conjugate showed a dose-response against tumor and endothelial cells but was generally less effective than the free Dox. The authors speculated this was due to a delayed Dox release. Electrostatic adsorption of NGR peptide targeting ligand to the surface of the micelle enables enhanced uptake and targeting toward both mitogenic endothelial (HUVEC) and tumor cells (HepG2, MCF7). Interesting, a plasmid expressing GFP was included as part of the micelle, raising the possibility of delivering both antitumor genes and Dox to the tumor. These in vitro studies also await in vivo experiments for validation [22].

\section{Alternative carriers}

Exosomes are one of the newest carriers to be used to transport Dox $[23,24]$. Exosomes are a subclass of extracellular vesicles with sizes ranging from $30 \mathrm{~nm}$ to $200 \mathrm{~nm}$, which offer therapeutic potential to deliver agents. Dox loaded exosomes $(6 \mathrm{mg} / \mathrm{kg})$, administered iv twice weekly, completely inhibited the growth of MDA-MB-231 tumor xenografts [24]. The efficacy was similar to Doxil'. In a syngeneic model of high grade serous ovarian cancer, the exosome-Dox $(6 \mathrm{mg} / \mathrm{kg})$ inhibited tumors significantly more than the maximal tolerated of free Dox $(3 \mathrm{mg} / \mathrm{kg})$. Notably, at their maximum tolerated dosages, Exo-Dox $(6 \mathrm{mg} / \mathrm{kg})$ showed no cardiotoxicity in this study whereas the free Dox ( $3 \mathrm{mg} / \mathrm{kg}$ ) did. The reduced toxicity of ExoDox may be due its limited ability to cross the myocardial endothelium [24].

In other studies, Dox was conjugated to magnetic carriers, where the drug could be directed to tumors with an external magnet. Wuang and colleagues coated paramagnetic nanoparticles with polymethacrylic acid to which Dox was conjugated via $\mathrm{pH}$ sensitive bonds [25]. Increased rates of Dox release from the NP at lower $\mathrm{pH}$ ( $\mathrm{pH}-5.5)$ were associated with greater killing of MDA-MB-231 cells. A combination of lower $\mathrm{pH}$ and preheating the $\mathrm{NP}$ to $42^{\circ} \mathrm{C}$, which may further increase the release of Dox, enhanced cell killing. Because paramagnetic NP that accumulate in the acidic environment of tumors may heat up when placed in a magnetic field, this approach offers great promise to target doxorubicin specifically to solid tumors. Moreover, magnetic fields have been used to target superparamagnetic iron oxide NPs (SPIONS) specifically toward tumors in vivo. Thus far, though,
SPIONS loaded with Dox have been limited to in vitro studies [26,27]. In one study, a pegylated SPION loaded with Dox demonstrated spectral fluorescence consistent with endocytic internalization and showed similar cytotoxicity as free Dox toward MCF7 breast cancer cells [26].

\section{Targeting Doxorubicin Resistance}

NPs can be used to limit tumor drug resistance by bypassing the efflux pump through cellular uptake. Free Dox is passively transported through the cellular membrane, making it susceptible for efflux pumps. In contrast, most of the NPs discussed in this review may overcome resistance through induction of endocytic drug uptake. Since this type of entry and intracellular release of Dox is not associated with the cellular membrane and efflux pumps, the cellular membrane efflux of Dox can be avoided. Nonetheless, this section will focus on nanoparticles that combine a Dox payload with efflux inhibitors or with inhibitors directed toward alternative Dox resistant mechanisms (MDR1/P-gp, c-Jun, BCL-2).

To advance the efficacy of Dox against resistant cells, one study evaluated incorporation of Dox with a DNAzyme (Dx), which targeted the transcriptional factor C-Jun, into a nanoparticle (Figure 2) [28]. This report was in part stimulated by a previous study that the combination of free Dox and a nanoparticle transporting C-Jun DNAzyme (Dx) almost completely inhibited tumor growth [29]. C-Jun is a transcriptional oncogene that promotes tumor growth and angiogenesis [30,31]. In addition, down-regulation of C-Jun is known to decrease the MDR1 transporter, which has an important role in the efflux of hydrophobic drugs such as doxorubicin in prostate cancer cells [32]. The mesoporous silica nanoparticles (MSN) were designed to release the DNAzyme early with a later sustained release of Dox. Compared to MSN particles incorporating only Dox, the MSNDxJun-Dox markedly enhanced cellular accumulation of doxorubicin. Consistent with these results, c-Jun and MDR1 were significantly reduced in cells treated by the MSN-DxJun-Dox group. Whereas both Dox and the c-Jun DNAzyme were important in reducing cell invasiveness (via the Matrigel assay), the DNAzyme had a fundamental role in reducing migration with an in vitro assay. Despite the low loading capacity of the MSN for Dox, they exhibited significant activity against prostate cancer cells. A potential advantage of these NPs was reduced toxicity from Dox. Similarly, another study also demonstrated

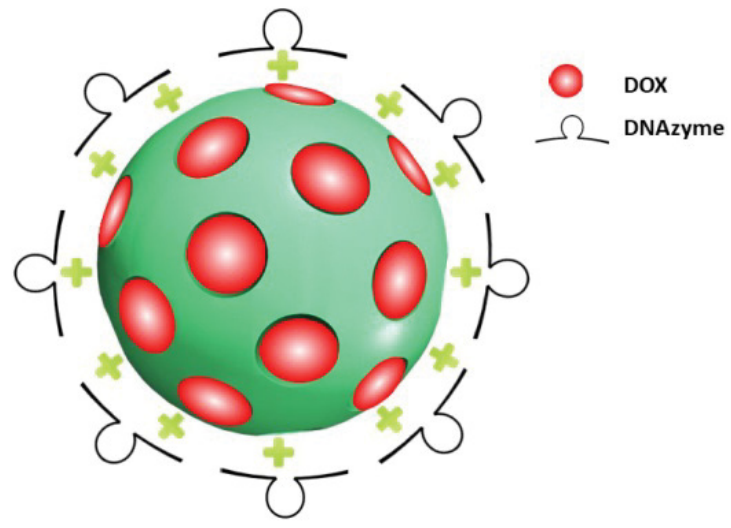

Figure 2: MSN with DNAzyme on the surface and Dox inside pores. The mesoporous silica nanoparticles (MSN) were designed to release the DNAzyme early with a later sustained release of Dox. 
the importance of the temporal release of an siRNA targeting the resistant Pgp gene and Dox [33,34].

The above strategies utilized the reduction of pump efflux transporter proteins (i.e., MDR1/P-glycoprotein) to increase the sensitivity of malignant cells to Dox. Another approach to treat chemotherapy-resistant tumor cells is to reduce non-pump proteins such as the anti-apoptotic BCL-2 protein. Chen et al. investigated codelivery of doxorubicin and siBcl2 with a MSN NP (MSN-siBcl2-Dox), using a doxorubicin-resistant ovarian cell line (A2780/AD) [35]. The siRNA was electrostatically attached to the outside of the MSN NP, providing early release upon uptake into the cell, whereas the Dox was attached internally by sulfhydryl-sensitive bonds and released later. The cyto-toxicity of MSN-siBcl2-Dox toward A2780/AD cells was 132fold greater than free Dox. Interestingly, the Bcl 2 siRNA delivered by the MSN reduced $\mathrm{Bcl} 2 \mathrm{mRNA}$ levels by $80 \%$.

Liu et al. utilized the multifunctional small molecule, quercetin, to reverse the resistance of tumor cells, with several novel aspects to the nanoparticle delivery of Dox. The study combined quercetin and a mesoporous silicon nanoparticle to deliver Dox to sensitive and resistant breast cancer cells [36]. Dox was attached to the quercetin through a $\mathrm{pH}$-sensitive coordination bond between iron and Dox. Dox was released $(\sim 80 \%)$ from the NP within 24 hours at $\mathrm{pH} 5$, the approximate $\mathrm{pH}$ of late endosomes. In contrast, relatively little of the Dox (15\%) was released at $\mathrm{pH}$ 7.4. Quercetin enhanced the uptake of the nanoparticle as well as reversed multiple drug resistance. To reverse drug resistance, quercetin needs to be released from the NP. The investigators provided evidence that the quercetin was released from the NP by incubating the NP with proteases. Further evidence that supports the release of quercetin comes from the inhibitory in vitro data. The quercetin-Dox- NP showed marked inhibitory activity in vitro toward both sensitive and resistant cells that was equivalent to the combined free doxorubicin and quercetin treatment.

\section{DNA Intercalated Dox NP}

DNA was one of the earliest carriers of an anthracycline to demonstrate antitumor activity [37,38]. At the higher dose of daunorubicin $(2.5 \mathrm{mg} / \mathrm{kg})$, the DNA: daunorubicin complex prolonged the life-span of mice bearing L1201 tumors compared to free daunorubicin. About $30 \%$ of mice survived at day 40 treated with the DNA-daunorubicin complex whereas all mice treated with the free drug died prior to day 20 . These early studies stimulated additional reports to combine an anthracycline (i.e., doxorubicin) with DNA or RNA, and later experiments were directed toward solid tumors. In addition to Dox binding to RNA/DNA aptamers, doxorubicin-intercalated nucleic acid "conjugates" have been integrated into polymeric or liposomal carriers. Notably, many other promising NPs targeting DNA to tumors have not yet been tested as carriers of Dox [39-41].

Most articles indicate that Dox binds with higher affinity to GC base pairs (bp) of DNA than others [42-44]. Nevertheless, one group reported that base pairs of adjacent CA bind anthracyclines tightly and release them slower than adjacent GC $[45,46]$. Despite the high affinity of Dox for DNA, the bound Dox is in equilibrium with free Dox $[45,47]$. Upon Dox binding to DNA, its fluorescence is quenched enabling determination of entrapment efficiency and loading capacity [48].

\section{Aptamers: ligands and carriers}

Bagalkot and colleagues intercalated doxorubicin not with DNA but with an RNA aptamer [49]. Maximal quenching of the Dox fluorescence occurred at about 1: 1 molar ratio. Because Dox binds strongly to GC sequences, the quenching studies were consistent with the one GC sequence in the aptamer. The RNA aptamer targeted the PMSA receptor on LNCap prostate cancer cells. The physical conjugate of the aptamer-Dox did not markedly affect the targeting of the aptamer. The binding ability of aptamer-Dox conjugate for LNCaP cells was $84 \%$ of that by the unmodified aptamer, suggesting that the Dox conjugate did not significantly affect the targeting of the aptamer. Punctate staining in the cytosol of LNCaP cells observed with the aptamer-Dox conjugate was consistent with an endocytic uptake. To validate these uptake studies, inhibition of cell growth was significantly more with the aptamer-Dox conjugate in the LNCaP cells than the conjugate in PC-3 cells, which did not express LNCaP receptors. Dox alone had similar inhibitory in both cell lines, indicating that the inhibitory differences were due to the conjugate and not due to resistance of the cells. Similarly, another laboratory targeted MUC1 expressing MCF-7 cells [50] with a pegylated aptamer-Dox conjugate. Whereas in vitro studies showed about a 70\% inhibition of MCF-7 cells with the conjugate, the non-expressing MUC1 cells, showed only about $20 \%$ inhibition compared to control cells.

Although the aptamer may have a dual purpose as a targeting ligand and as a carrier of Dox, the aptamer may serve solely as a ligand for the nanoparticle. In these instances, there have been several interesting reports that include a separate DNA domain to bind Dox. Only one of these studies has extended in vitro efforts to tumor inhibitory studies. Charbgoo et al. incorporated Dox inside targeted "DNA micelles" to inhibit cancer cells [48]. Furthermore, the micelles contained a cytotoxic KLA peptide to enhance the cytotoxic effect of the NPs toward cancer cells. Whereas the KLA peptide was conjugated to the NP, Dox via intercalation with DNA was loaded into the NP. To reduce the cytotoxic effects of Dox-KLA micelles toward nonmalignant cells, a DNA-aptamer, which targets the overexpressed Mucl on adenocarcinoma cells, was included on the exterior of the NP. An excess of the free aptamer reduced toxicity of the Dox KLA antiMuc NP in a Muc1 overexpressing cancer cell line (MCF7), indicating that cellular uptake of the micelle was necessary for the Dox activity. The cytotoxicity toward breast cancer cells in vitro was enhanced by combining Dox and KLA into the micelles compared to the cytotoxic effect of Dox- or KLA-only micelles. One dose of the targeted Dox KLA anti-Muc1 NP $(2.5 \mathrm{mg} / \mathrm{kg})$ inhibited tumor growth (C26, a mouse colon carcinoma) significantly more than untreated or free doxorubicin groups $(\mathrm{P}<0.05)$. Furthermore, the targeted NP prolonged survival with $60 \%$ of the mice alive at day 30 . In contrast, all mice in the untreated and free Dox groups died by days 21 and 30, respectively.

Dox has also been incorporated into a GC rich oligonucleotide in which an ATP responsive aptamer was annealed [51]. Moreover, the GC-rich oligonucleotide together with a miR34-a was complexed to a PEI cationic carrier. They established that doxorubicin was released from the aptamer-GC construct when exposed to intracellular ATP concentrations of $4 \mathrm{mM}$. In contrast, extracellular concentrations of ATP $(0.4 \mathrm{mM})$ only minimally released doxorubicin. Thus, the aptamer was essential for the intracellular release of the Dox. When human lung cancer A549 cells were incubated with the PEI/GC-Dox/ mir-34a, there was increased apoptosis compared to either the PEI/ GC-Dox or PEI/GC-Dox alone. The greatest reduction in cell number and cell migration was seen with the PEI/GC-Dox/mir34a. Consistent with apoptosis and inhibition of cell migration, co-delivery of Dox and mir34a with this NP resulted in a decrease of several proteins including PARP, MMP9, Notch1, Bcl-2, and procaspase 3. A decrease in Bcl-2 by this nanoplex also suggests that this approach may be effective in reducing Dox-resistance in tumor cells. 
To target PMSA expressing prostate cancer cells, Dox was intercalated in a rolling circle DNA [52]. The rolling circle incorporated a PMSA aptamer, a pH-sensitive spacer to release the Dox, and a GCenriched segment to bind the Dox. The rolling circle NP had a mean size of $234 \mathrm{bp}$ and released Dox readily in an acidic environment compared to a physiological environment ( $80 \% v s .20 \%$ release in $3 \frac{1}{2}$ hours). Moreover, the targeted NPs were taken up by PMSA positive cells significantly more than PMSA-negative cells. However, no inhibitory studies were reported with the Dox-loaded NPs.

\section{Plasmids, chromosomal, and oligonucleotide DNA}

One group has looked at two different strategies (intravenous or local delivery) to combine Dox with immunostimulatory $\mathrm{CpG}$ to reduce tumor growth $[47,53]$. In both studies, the combination of Dox and CpG DNA was at least additive. In a co-culture study with colon carcinoma cells (colon 26/luc) and macrophages (RAW264.7), the results showed that immunostimulatory $\mathrm{CpG}$ plasmids and Dox were at least additive in their anti-proliferative effects against the colon cancer cells. For in vivo studies with immunocompetent $\mathrm{BALB} / \mathrm{c}$ mice, a $\mathrm{CpG}$ plasmid-Dox conjugate was injected intravenously. CpG plasmids inoculated into mice increased TNF $\alpha$ and IL12 levels. In colon cancer cells implanted into the liver, the CpG-Dox combination accumulated significantly more in the tumor tissue than free Dox. Consistent with this finding, the growth of colon cancer cells in the liver was reduced considerably with the Dox-CpG than free Dox. The CpG plasmid-Dox group showed more antitumor activity than the CpG, Dox, or CpGfree-Dox groups.

Chen et al. determined that Dox and c-myc siRNA (si-myc) NPs inhibited solid tumors [54]. The carriers of these therapeutic agents were pegylated liposomes in which a targeting NGR peptide ligand was attached. Whereas Dox $(0.3 \mathrm{mg} / \mathrm{kg})$ did not inhibit tumor growth in a mouse model compared to an untreated group, the si-myc siRNA NP reduced tumor growth moderately. Interestingly, the Dox-si-myc-NP reduced tumor growth significantly more that si-myc NPs. Both Dox, which intercalated with thymus DNA, and the si-myc were entrapped within the liposomes. Notably, the dose of Dox was significantly lower than in most other studies in which the dose of Dox was $5 \mathrm{mg} / \mathrm{kg}$ or higher. In addition to the targeting ligand NGR, many tumor-selective ligands are promising for conjugation to the surface of the NP [55].

One of the more novel carriers of Dox is the tetrahedron DNA structure (Figure 3) [56]. A tumor penetrating peptide, which targets neuropilin-1 (NRP-1), was conjugated to the structure. The size of the tetrahedron structure, together with the Dox, was about 15 $\mathrm{nm}$ in size. There were approximately forty Dox molecules in each targeted tetrahedron. Compared to an untargeted form, the uptake of the targeted tetrahedron structure was significantly greater in a glioblastoma cell line. Consistent with greater uptake, the targeted tetrahedron structure had a greater inhibitory effect (IC50-2.478 $\mu \mathrm{M})$ than the untargeted structure (IC50-4.785 $\mu \mathrm{M}$ ). In a cell line that did not have the neuropilin-1 receptor, no difference in the uptake or inhibition was observed with the targeted or untargeted tetrahedron nanoparticles. Moreover, the tetrahedron structure was relatively stable to biological media compared to degradation of double stranded DNA structure within $4 \mathrm{~h}$. Moreover, Dox was more readily released at an acidic $\mathrm{pH}$ than at physiological $\mathrm{pH}$, suggesting release in lysosomes.

\section{Progress with Local Therapy}

Systemically administered anticancer treatments are greatly limited by extensive side effects mainly due to nonspecific distributions in vivo. In contrast to systemic delivery, local delivery of Dox increases drug delivery to the tumor with reduced toxicity to normal tissues. Moreover, local therapy offers an alternative to surgery or radiation in cancers with high local recurrence or in primary or metastatic cancers juxtaposed to vital structures. Doxil ${ }^{\circ}$ has been approved for systemic use, and whereas doxorubicin can be administered intratumorally, preclinical studies demonstrate that this route has significant side effects at dosages sufficient to control the growth of tumors [57,58]. There are several approaches that have been used for intratumor delivery of doxorubicin (Table 1). Solution-based biomaterials containing Dox rapidly become gels once injected into the tumors. The colloidal solution (sol)-gel change may be due to thermosensitive biomaterials or due to exchange of buffers. Alternatively, nanoparticles either alone or embedded in a matrix have also shown efficacy in reducing tumor size locally.

To address the problem of high local recurrence in breastconserving therapy, several investigators have examined Dox embedded in different nanomaterials. Yaun et al. [59] designed Doxloaded nanofibers which released Dox in two phases-one an early release and the other a sustained release. To achieve these different rates of release, the nanoparticle is comprised of two components: the electrospun polylactic acid (PLLA) polymer and the mesoporous silica nanoparticle (MSN). Whereas PLLA fibers can release Dox quickly, the MSN which are incorporated in the PLLA fibers showed sustained release of the Dox over 16 weeks. Various Dox loaded scaffolds were implanted into the remnant MDA-MB-231 tumors. Whereas tumors of the Dox-loaded PLLA fibers and PLLA-(MSN-Dox) resulted in early and late necrosis (and apoptosis), respectively, tumors of the PLLA-(MSN-Dox)-Dox had enhanced and sustained necrosis (and apoptosis). The in vivo histological data corresponded to the release of Dox from these different scaffolds.

Nanofiber gels containing Dox to treat breast cancer locally (Figure 4) were also formed by a different strategy [60]. Oppositely charged peptides that contained aliphatic alkyl tails self-assembled into gels. Initially, Dox was mixed with the negatively charged peptide (LaurylVVAGEEE) and co-assembly was initiated by the addition of positively charged peptide (Lauryl-VVAGKKK) at pH, 7.4. Encapsulation of Dox was $100 \%$ in this gel with sustained release of Dox for 7 days from the gel under in vitro conditions. Based on released properties

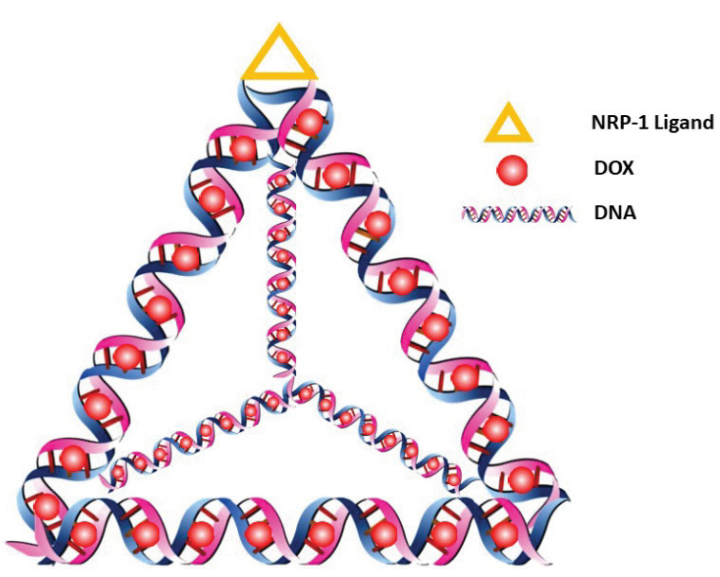

Figure 3: Dox intercalated within pyramidal DNA. With approximately forty Dox molecules in each tetrahedron, the size of the tetrahedron was about 15 $\mathrm{nm}$. A tumor-targeting ligand such as the one for neuropilin-1 (NRP-1) can be conjugated to the structure. 
Citation: Zhao N, Woodle MC, Mixson AJ (2018) Advances in Delivery Systems for Doxorubicin. J Nanomed Nanotechnol 9: 519. doi: 10.4172/21577439.1000519

Page 6 of 9

\begin{tabular}{|c|c|c|c|c|c|}
\hline Biomaterials & $\begin{array}{c}\text { Intratumoral injection } \\
\text { metod }\end{array}$ & Cells & Results & Other comments & Reference \\
\hline $\begin{array}{l}\text { PLLA nanofibers, } \\
\text { MSN hybrid }\end{array}$ & $\begin{array}{l}\text { Implantation of } \\
\text { nanofiber scaffold into } \\
\text { remnant Tumor }\end{array}$ & $\begin{array}{l}\text { MB-MDA-231, } \\
\text { human breast tumor; } \\
\text { SC }\end{array}$ & $\begin{array}{c}\text { Greater tumor necrosis and apoptosis } \\
\text { in PLLA-Dox/MSN-Dox than PLLA/ } \\
\text { MSN-Dox or PLLA-Dox/MSN }\end{array}$ & $\begin{array}{c}\text { Early (PLLA) and Late (MSN) Phase of } \\
\text { Releasing Dox }\end{array}$ & Yuan et al. [59] \\
\hline Peptide amphiphiles & $\begin{array}{l}\text { Oppositely charged } \\
\text { peptide amphiphiles } \\
\text { trigger gel formation; } \\
\text { injection adjacent to } \\
\text { tumor }\end{array}$ & $\begin{array}{l}\text { 4T1, a murine } \\
\text { carcinoma cell line; } \\
\text { SC }\end{array}$ & $\begin{array}{l}\text { At end of study, there was about a } \\
50 \% \text { reduction in tumor size }(10 \mathrm{mg} / \\
\mathrm{kg}) \text { compared to control }\end{array}$ & $\begin{array}{l}\text { Enhanced apoptosis (increased caspase } \\
3 \text { staining); May be difficult to control gel } \\
\text { formation in clinical studies as currently } \\
\text { designed; Initial tumor size } 100 \mathrm{~mm}^{3}\end{array}$ & Cinar et al. [60] \\
\hline Polyphosphazene & $\begin{array}{l}\text { Thermosensitive } \\
\text { emulsion to gel; IT } \\
\text { injection }\end{array}$ & $\begin{array}{l}\text { SNU-601, human } \\
\text { gastric carcinoma; } \\
\text { SC }\end{array}$ & Tumor regression of xenografts & $\begin{array}{c}\text { During the } 28 \text { days of study, the weight } \\
\text { of the polymer-Dox treated groups was } \\
\text { similar to that of the saline-treated; initial } \\
\text { tumor size } \sim 400 \mathrm{~mm}^{3}\end{array}$ & Chun et al. [57] \\
\hline PEG -b-PCL & $\begin{array}{l}\text { Thermosensitive } \\
\text { emulsion to gel; IT } \\
\text { injection }\end{array}$ & $\begin{array}{l}\text { B16F10, mouse } \\
\text { melanoma; SC }\end{array}$ & $\begin{array}{l}\text { Dox-gel reduced tumor size by about } \\
90 \% \text { compared to saline-treated group }\end{array}$ & $\begin{array}{c}\text { Biodistribution of gel-dox group shows } \\
\text { low levels of dox in normal tissues; initial } \\
\text { tumor size } 100-150 \mathrm{~mm}^{3}\end{array}$ & Kang et al. [62] \\
\hline $\begin{array}{c}\text { Phospholipid, } \\
\text { medium chain } \\
\text { triglycerides, ethanol }\end{array}$ & $\begin{array}{c}\text { Emulsion to Gel; } \\
\text { solvent exchanged; IT } \\
\text { injection }\end{array}$ & $\begin{array}{l}\text { Sarcoma-180, a } \\
\text { mouse sarcoma (in } \\
\text { vivo);SC } \\
\text { MCF7, a human } \\
\text { breast carcinoma } \\
\text { (in vitro) }\end{array}$ & $\begin{array}{l}\text { More than } 80 \% \text { tumor inhibition with } \\
\text { gel-Dox group ( } 30 \mathrm{mg} / \mathrm{kg} \text { ) compared } \\
\text { to control; also prolonged survival } \\
\text { compared to control saline group; all } \\
\text { mice treated with free dox were dead } \\
\text { by } 4 \text { days }\end{array}$ & $\begin{array}{l}\text { Exchange ethanol for interstitial fluid } \\
\text { to trigger gel formation; weight of mice } \\
\text { treated with gel-dox was similar to } \\
\text { control; initial tumor size } \sim 500 \mathrm{~mm}^{3}\end{array}$ & Wu et al. [58] \\
\hline $\begin{array}{c}\text { Phospholipid E-80, } \\
\text { medium chain } \\
\text { triglyceride, ethanol }\end{array}$ & $\begin{array}{c}\text { Emulsion to Gel; } \\
\text { solvent exchanged; IT } \\
\text { injection }\end{array}$ & $\begin{array}{l}\text { MCF7/Adr, a } \\
\text { human breast cell } \\
\text { line resistant to } \\
\text { doxorubicin; SC }\end{array}$ & $\begin{array}{l}\text { Combination of Dox (12 mg/kg) and } \\
\text { P-gp inhibitor (W198) in gel was most } \\
\text { effective with } 75 \% \text { inhibition compared } \\
\text { to saline-control; Dox in gel inhibited } \\
\text { tumor size by } 52 \% \text {. }\end{array}$ & $\begin{array}{c}\text { Exchange ethanol for tumor fluid; blood } \\
\text { counts were within normal limits and no } \\
\text { cardiotoxcity for Dox-W198-gel initial } \\
\text { tumor size } \sim 100 \mathrm{~mm}^{3}\end{array}$ & Luo et al. [63] \\
\hline Zein protein & $\begin{array}{c}\text { Emulsion to Gel; } \\
\text { solvent exchanged; IT } \\
\text { injection }\end{array}$ & $\begin{array}{l}\text { H-29, a human } \\
\text { colorectal cancer; } \\
\text { SC }\end{array}$ & $\begin{array}{c}\text { Dox-gel }(5 \mathrm{mg} / \mathrm{kg}) \text { reduced the size of } \\
\text { tumors by more than } 90 \% \text {. }\end{array}$ & $\begin{array}{c}\text { Exchange glycerol formal for tumor } \\
\text { interstitial fluid; Zein is major storage } \\
\text { protein for corn; initial tumor size } \sim 100 \\
\mathrm{~mm}^{3}\end{array}$ & Shen et al. [64] \\
\hline X-linked DNA & $\begin{array}{l}\text { Gel-like biomaterial } \\
\text { cross-linked by } \\
\text { T4 DNA ligase; IT } \\
\text { injection X } 2\end{array}$ & $\begin{array}{l}\text { Colon } 26, \text { a mouse } \\
\text { colon carcinoma (in } \\
\text { vivo); SC } \\
\text { RAW264.7, a } \\
\text { macrophage (in } \\
\text { vitro) }\end{array}$ & $\begin{array}{l}\text { The immunostimulatory Dox-CpG-gel } \\
(0.25 \mathrm{mg} / \mathrm{kg}) \text { was most effective of } \\
\text { the treatments, inhibiting the size of } \\
\text { tumors by about } 60 \% \text { compared to } \\
\text { control. TNF- } \alpha \text { from RAW264.7 cells } \\
\text { was stimulated by CpG-Dox-gel }\end{array}$ & $\begin{array}{c}\text { Contains CpG immunostimulatory } \\
\text { motif; experiments performed in } \\
\text { immunocompetent Balb/c mice; TNF- } \alpha \\
\text { from RAW264.7 cells was stimulated by } \\
\text { CpG-Dox-gel }\end{array}$ & $\begin{array}{l}\text { Nishikawa et } \\
\text { al. [53] }\end{array}$ \\
\hline $\begin{array}{c}\text { PEG-PCL-PLL, } \\
\text { PLGA microcapsules }\end{array}$ & $\begin{array}{c}\text { Thermosensitive } \\
\text { emulsion to gel (PEG- } \\
\text { PCL-PLL); IT }\end{array}$ & $\begin{array}{l}\text { B16F10, a mouse } \\
\text { melanoma; SC }\end{array}$ & $\begin{array}{c}\text { Early release of 5-FU from PLL } \\
\text { gel and later release of Dox from } \\
\text { microcapsules inhibited tumor activity } \\
\text { more than } 90 \% \text { compared to saline } \\
\text { control. The combined therapy had } \\
\text { greater activity than the 5-FU gel } \\
\text { alone. }\end{array}$ & $\begin{array}{l}\text { PEG-PCL-PLL with } 5 \text { FU (early phase); } \\
\text { Dox-loaded PLGA microcapsules (late } \\
\text { phase); initial tumor size, } 150-200 \mathrm{~mm}^{3} ; \\
\text { tumors extremely large in control groups } \\
\text { at end of study. }\end{array}$ & Kim et al. [65] \\
\hline Gold nanoparticles & $\begin{array}{c}\text { Gold nanoparticles } \\
\left(5 \mathrm{~mm}^{3}\right) \text {; multiple IT } \\
\text { injections every } 2 \text { to } \\
3 \text { days }\end{array}$ & $\begin{array}{l}\text { B16 (resistant } \\
\text { to Dox), mouse } \\
\text { melanoma, SK- } \\
\text { MEL-28, human } \\
\text { melanoma; SC }\end{array}$ & $\begin{array}{l}\text { Marked inhibition in tumor size for } \\
\text { mouse }(\sim 85 \%, \text { day } 16) \text { and human } \\
\text { melanomas }(\sim 100 \%) \text { treated with } \\
\text { Dox-gold conjugate; Dox-gold }(0.2 \\
\text { mg/kg per injection) showed greater } \\
\text { antitumor activity than Dox alone. }\end{array}$ & $\begin{array}{l}\text { Endocytosis by tumor of NP is thought } \\
\text { to be important for tumor inhibition; } \\
\text { Initial tumor size } 150 \mathrm{~mm}^{3}\end{array}$ & Zhang et al. [66] \\
\hline
\end{tabular}

Table 1: Local Delivery of doxorubicin.

and stability of the gel, the $1 \%$ gel was selected for in vivo testing of the gel-incorporating Dox. The gels did not show any cytotoxicity in vivo as indicated by the normal histology of organs. Furthermore, local in vivo injection of Dox $(10 \mathrm{mg} / \mathrm{kg})$ encapsulated gels adjacent to the tumor site reduced tumor size significantly more than free Dox $(\sim 33 \%)$ or control PBS ( $50 \%)$ injections. The tumors of the Dox-gel treated group also showed increased apoptosis compared to control or Doxtreated groups.

The biodegradable polymeric hydrogel, poly(organophosphazene), is an injectable delivery system that has been used to deliver Dox to treat solid tumors in murine mouse models [57,61]. Poly(organophosphazene) transforms from an emulsion to a gel at body temperature. In vitro studies at $37^{\circ} \mathrm{C}$ in PBS showed a steady release of about $60 \%$ of Dox by 28 days. Although intratumoral injections of the Dox treatment alone initially showed greater antitumor efficacy (SNU601, a gastric carcinoma), by day 12 the tumor gel-Dox treatment inhibited tumor growth similar to the Dox-alone treatments $(30 \mathrm{mg} / \mathrm{kg}$ ). At day 12, all mice in the Dox-treated group were euthanized because of significant weight loss. Compared to the control saline-treated group in which their tumors had increased $200 \%$ at day 28 , the low dose $(22.3$ $\mathrm{mg} / \mathrm{kg})$ and high dose $(44.5 \mathrm{mg} / \mathrm{kg})$ groups of the polymer-Dox treated groups had tumors which decreased by $50 \%$ and $75 \%$, respectively. Notably, the toxicity of the gel treated groups was markedly less than the Dox only treated group. Whereas all mice treated with Dox alone $(30 \mathrm{mg} / \mathrm{kg}$ ) were euthanized by day 12 due to the high toxicity of the drug, there were no significant untoward effects from the polymer-Dox gel groups for 28 days as evidenced by their similar weight curves to the saline-treated group. The investigators speculate that Dox is release at least in part from the degraded gel by lysosomal enzymes. In another similar study, investigators used a thermosensitive biodegradable diblock polymer ([polyethylene glycol]-b-polycaprolactone), which formed a gel at $37^{\circ} \mathrm{C}[62]$. In mice bearing $\mathrm{B} 16 \mathrm{~F} 10$ cancer xenografts, a single intratumoral injection of Dox-loaded MP gel $(0.4 \mathrm{mg}, 20 \mathrm{mg} /$ 


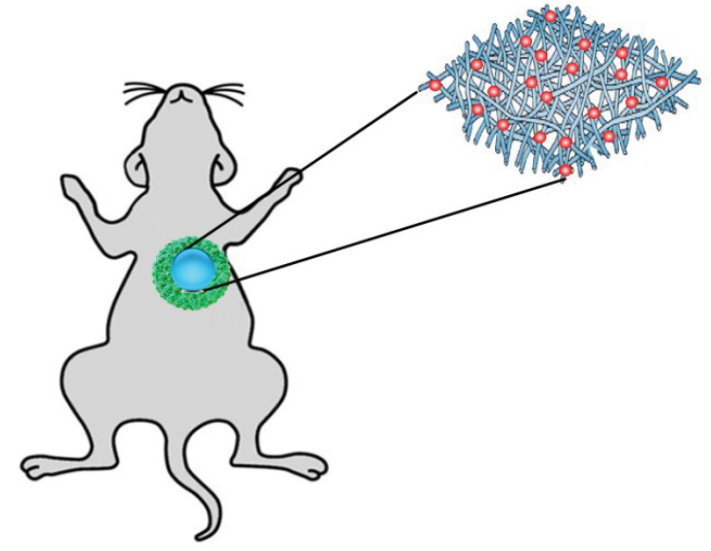

Figure 4: Intratumor location of nanofiber gel with doxorubicin. A solution of oppositely charged peptides and doxorubicin self-assembled into gels. The gel with sustained release of Dox for 7 days had marked antitumor activity.

$\mathrm{kg}$ ) inhibited the growth of tumors similar to repeated intratumoral injections of Dox-only.

With the soluble solution of a phospholipid (E80), medium chain triglycerides, and ethanol (PME), an intratumoral gel was formed containing high levels of Dox [58]. Upon injection into the tumor, the ethanol diffused from PME enabling the gel to form. The optimal PME ratio that allowed sustained release of Dox over a 14 day period was 72:17:11. The mice bearing sarcoma 180 tumors had significant reduction in their tumors compared to the saline treated group. During the 14 days of therapy, there was little to no increase in the size of the tumors. The dose of Dox entrapped within the gel of the tumor was $30 \mathrm{mg} / \mathrm{kg}$. Compared to the intravenous Dox treatment group, there was significantly more apoptosis in gel-Dox treated group. Moreover, the tumor-bearing mice treated with the Dox-gel showed no toxicity during the 14 days of treatment. Their weight gain was similar to saline treated mice. Consistent with the low toxicity, levels of Dox in the serum from the gel were low and remained at $20-25 \mathrm{ng} / \mathrm{mL}$ for several days. Moreover, at various times up to the $14^{\text {th }}$ day, the levels of Dox in the tumor remained high, yet normal tissues had very low levels of Dox. In contrast, concentrations in serum of Dox-only $(30 \mathrm{mg} / \mathrm{kg})$ injected in the tumor had significantly higher concentration of Dox transiently $(2849 \mathrm{ng} / \mathrm{mL}$ ). The toxicity of the Dox-only was marked in that all mice died by 4 days, and similarly, the mice injected IV with Dox died by the $7^{\text {th }}$ day. Although administering the dose of Dox in which the mice did not die from toxicity would have been helpful, this study shows a promising biocompatible gel comprised of simple components [58].

Similarly, a phospholipid-based in situ forming gel platform was developed for co-delivery of Dox and bromotetrandrin (W198). By inhibiting the cellular efflux of Dox from tumor cells, W198 can enhance the sensitivity of resistant tumors to Dox. The gel showed in vitro sustained release of these two antitumor agents over a 20-day period. With a single intratumoral injection, the gel-Dox-W198 (12 mg/ $\mathrm{kg}$ ) had the greatest inhibitory activity compared to the other treatment groups. Whereas the gel-Dox-W198 inhibited resistant MCF7/Adr tumors by $75 \%$, the gel-Dox reduced tumor size by $52 \%$ compared to the control saline group. In contrast to the intratumoral injection of the free solution of Dox and W198, the gel delivery platforms had blood counts (hematocrit, RBC, WBC) within normal limits, and there was no cardiotoxicity [63].
To treat colorectal tumors in a mouse model, a protein, zein, has been used to form a gel in which Dox was incorporated [64]. Zein is a major storage protein that comprises about $50 \%$ of the protein of corn. The zein-Dox was soluble in glycerol formal and became a gel as the glycerol formal was replaced by physiologic buffer or interstitial tumor fluid. In vitro release of Dox from the gels extended up to 7 days. Intratumoral injections of mice treated with Dox-loaded gels $(5 \mathrm{mg} /$ $\mathrm{kg}$ ) markedly reduced the tumor size compared to mice treated with Dox-only or the untreated groups. The concentration of Dox in the zein-Dox group was decreased in the blood, heart, and lungs compared to the free drug, raising the potential of reduced side effects. Nevertheless, the immunogenicity of zein in humans is a potential concern for this strategy.

As discussed earlier, the group of Nishikawa injected intravenously a Dox-CpG plasmid to reduce tumor growth [47]. In a later and very novel study, this group prepared a hydrogel comprised of interlinking $\mathrm{X}$-shaped CpG oliogonucleotides [53]. Combining Dox with the immunogenic $\mathrm{CpG}$ hydrogel resulted in prolonged inhibition of colon carcinomas in vivo compared to Dox-only, hydrogel alone, or CpGfree hydrogel.

Kim and colleagues developed a complexed delivery platform to deliver 5-FU and Dox [65]. The poly (lactic-co-glycolic acid (PLGA) microcapsule with the Dox was added to the thermosensitive copolymer PEG-(polycaprolactone-poly-L-lactic acid) emulsion containing 5-FU. This emulsion was free flowing at room temperature and gellified at body temperature. The delivery system was designed to release 5-FU in the first stage and Dox in the second stage. High levels of both drugs with this formulation were found in the tumor with little to negligible levels in normal tissues. Compared to either drug alone, the combination of 5-FU and Dox inhibited significantly more the rapidly growing B16F10 melanoma tumors in vivo. The size of the tumors in this combination-treated group decreased by about $95 \%$ compared to the size of the control saline-treated group.

Of the recently developed therapies tested for intratumoral delivery of Dox, one study was distinctive in that only nanoparticles were injected [66]. They found that intratumoral injection of Dox conjugated to ultra-small gold nanoparticles $(\sim 5 \mathrm{~nm})$ markedly inhibited tumor growth of mouse and human tumors. The injections were given intratumorally every 2 to 3 days with each dose of Dox containing $0.2 \mathrm{mg} / \mathrm{kg}$. On day 16 , the sizes of Dox-resistant B16 tumors in the PBS-, Dox alone-, and gold-Dox treatment groups were about 2000,550 , and $300 \mathrm{~mm}^{3}$, respectively. Concomitant with the marked reduction in tumor size, the gold-Dox treatment group had the greatest degree of apoptosis [66].

\section{Conclusion}

This review highlights the diverse number of NP carriers studied for enhanced therapeutic application of Dox. The diversity and novelty also include tumor targeting ligands and ligand linkages attached to these nanostructures. At least short term, these Dox-loaded NPs showed low toxicity compared to conventional Dox. Nevertheless, except for two studies of these alternative carriers of Dox [17,24], the remainder of the nanoparticles studied were not compared to FDAapproved nanoparticles such as Doxil ${ }^{\circ}$. This comparison would be helpful to ascertain whether these novel nanoparticles have advantages that would support clinical development.

One of the most immediate unmet needs for Dox is to address the frequent observance of drug resistance to therapy. Mesoporous silica nanoparticles have been the most commonly investigated carrier for 
the dual delivery of Dox and inhibitors targeting cellular resistance (to Dox). Dox-resistance in cell lines is dependent on both pump and non-pump mechanisms. Pump mechanisms include those that directly (i.e., MDR1/P-gp) or indirectly (c-Jun) increase levels of Dox efflux. Alternatively, since NPs containing Dox are endocytized and located near the perinuclear membrane, the cellular membrane efflux mechanisms may be less effective in lowering doxorubicin levels compared to free doxorubicin that passively enters the cell.

The most developed of the delivery systems are the local formulations impregnated with Dox. The local delivery systems show impressive inhibition of tumor growth in vivo. In addition to recurrence of local disease, primary malignancies such as brain glioma may also be treated with local therapy. The utility of local therapy with Dox compared to the surgical removal or radiation therapy of the tumor remains to be established. Nevertheless, local delivery platforms of Dox offer a great deal of promise for regional treatment of tumors, tumors impending on vital structures, or tumors that rarely metastasize.

\section{Acknowledgements}

This work was supported by the National Institutes of Health (R01-CA136938).

\section{Conflict of Interest}

The authors have no conflict of interest.

\section{References}

1. Chatterjee K, Zhang J, Honbo N, Karliner JS (2010) Doxorubicin cardiomyopathy. Cardiology 115: 155-162.

2. Denard B, Lee C, Ye J (2012) Doxorubicin blocks proliferation of cancer cells through proteolytic activation of CREB3L1. Elife 1: e00090.

3. Denard b, Pavia-Jimenez A, Chen W, Williams NS, Naina H, et al. (2015) Identification of CREB3L1 as a Biomarker Predicting Doxorubicin Treatment Outcome. PLoS One 10: e0129233.

4. Lupertz R, Watjen W, Kahl R, ChovoloY (2010) Dose- and time-dependent effects of doxorubicin on cytotoxicity, cell cycle and apoptotic cell death in human colon cancer cells. Toxicology 271: 115-121.

5. Singal RK, lliskovic N (1998) Doxorubicin-Induced Cardiomyopathy. N Engl J Med 339: 900-905

6. Carvalho C, Santos RX, Cardoso S, Correia S, Oliveira PJ, et al. (2009) Doxorubicin: the good, the bad and the ugly effect. Curr Med Chem 16: 3267 3285 .

7. Rafiyath SM, Rasul M, Lee B, Wei G, Lamba G, et al. (2012) Comparison of safety and toxicity of liposomal doxorubicin vs. conventional anthracyclines: a meta-analysis. Exp Hematol Oncol 1: 10.

8. Ngan YH, Gupta M (2016) A comparison between liposomal and nonliposoma formulations of doxorubicin in the treatment of cancer: An updated review. Archives of Pharmacy Practice 7: 1-13.

9. Rahman AM, Yusuf SW, Ewer MS (2007) Anthracycline-induced cardiotoxicity and the cardiac-sparing effect of liposomal formulation. Int $\mathrm{J}$ Nanomedicine 2 : $567-583$

10. Mitra S, Gaur U, Ghosh PC, Maitra AN (2001) Tumour targeted delivery of encapsulated dextran-doxorubicin conjugate using chitosan nanoparticles as carrier. J Control Release 74: 317-323.

11. Kim JH, Kim YS, Kim S, Park JH, Kim K, et al. (2006) Hydrophobically modified glycol chitosan nanoparticles as carriers for paclitaxel. J Control Release 111: 228-234

12. Trickler WJ, Nagvekar AA, Dash AK (2008) A novel nanoparticle formulation for sustained paclitaxel delivery. AAPS PharmSciTech 9: 486-493.

13. Jeong YI, Jin SG, Kim IY, Pei J, Wen M, et al. (2010) Doxorubicin-incorporated nanoparticles composed of poly(ethylene glycol)-grafted carboxymethyl chitosan and antitumor activity against glioma cells in vitro. Colloids Surf B Biointerfaces 79: 149-155.

14. Verma AK, Leekha A, Kumar V, Moin I, Kumar S (2018) Biodistribution and
In-vivo efficacy of doxorubicin loaded chitosan nanoparticles in Ehrlich Ascites Carcinoma (EAC) bearing Balb/C mice. J Nanomed Nanotechnol 9: 510

15. Mansouri S, Cuie Y, Winnik F, Shi Q, Lavigne P, et al. (2006) Characterization of folate-chitosan-DNA nanoparticles for gene therapy. Biomaterials 27: 20602065.

16. Lavertu M, Méthot S, Tran-Khanh N, Buschmann MD (2006) High efficiency gene transfer using chitosan/DNA nanoparticles with specific combinations of molecular weight and degree of deacetylation. Biomaterials 27: 4815-4824.

17. Lee CC, Gillies ER, Fox ME, Guillaudeu SJ, Fréchet JM, et al. (2006) A single dose of doxorubicin-functionalized bow-tie dendrimer cures mice bearing C-26 colon carcinomas. Proc Natl Acad Sci USA 103: 16649-16654.

18. Lelle M, Freidel C, Kaloyanova S, Tabujew I, Schramm A, et al. (2017) Overcoming drug resistance by cell-penetrating peptide-mediated delivery of a doxorubicin dimer with high DNA-binding affinity. Eur J Med Chem 130: 336-345.

19. Pranatharthiharan S, Patel MD, Malshe VC, Pujari V, Gorakshakar A, et al. (2017) Asialoglycoprotein receptor targeted delivery of doxorubicin nanoparticles for hepatocellular carcinoma. Drug Deliv 24: 20-29.

20. Xiong H, Zhou D, Qi Y, Zhang Z, Xie Z (2015) Doxorubicin-Loaded CarboraneConjugated Polymeric Nanoparticles as Delivery System for Combination Cancer Therapy. Biomacromolecules 16: 3980-3988.

21. Zhang Y, Yang C, Wang W, Liu J, Liu Q (2016) Co-delivery of doxorubicin and curcumin by $\mathrm{pH}$-sensitive prodrug nanoparticle for combination therapy of cancer. Sci Rep 6: 21225.

22. Liu C, Liu F, Feng L, Li M, Zhang J, et al. (2013) The targeted co-delivery of DNA and doxorubicin to tumor cells via multifunctional PEI-PEG based nanoparticles. Biomaterials 34: 2547-2564.

23. Tian Y, Li S, Song J, Ji T, Zhu M, et al. (2014) A doxorubicin delivery platform using engineered natural membrane vesicle exosomes for targeted tumo therapy. Biomaterials 35: 2383-2390.

24. Hadla M, Palazzolo S, Corona G, Caligiuri I, Canzonieri V, et al. (2016) Exosomes increase the therapeutic index of doxorubicin in breast and ovarian cancer mouse models. Nanomedicine (Lond) 11: 2431-2441.

25. Wuang SC, Neoh KG, Kang ET, Leckband DE, Pack DW (2011) Acid-Sensitive Magnetic Nanoparticles as Potential Drug Depots. AIChE J 57: 1638-1645.

26. Gautier J, Munnier E, Paillard A, Hervé K, Douziech-Eyrolles L, et al. (2012) A pharmaceutical study of doxorubicin-loaded PEGylated nanoparticles for magnetic drug targeting. Int J Pharm 423: 16-25.

27. Munnier E, Cohen-Jonathan S, Linassier C, Douziech-Eyrolles L, Marchais $H$ et al. (2008) Novel method of doxorubicin-SPION reversible association for magnetic drug targeting. Int J Pharm 363: 170-176.

28. Sun SP, Liu CP, Huang P, Chu CH, Chung MF, et al. (2017) A co-delivery nanosystem of chemotherapeutics and DNAzyme overcomes cancer drug resistance and metastasis. Nano Futures 1: 1-16.

29. Dass CR, Khachigian LM, Choong PF (2008) c-Jun knockdown sensitizes osteosarcoma to doxorubicin. Mol Cancer Ther 7: 1909-1912.

30. Vogt PK (2001) Jun the oncoprotein. Oncogene 20: 2365-2377.

31. Vleugel MM, Greijer AE, Bos R, van der Wall E, van Diest PJ (2006) c-Jun activation is associated with proliferation and angiogenesis in invasive breast cancer. Hum Pathol 37: 668-674.

32. Xia Y, Yang W, Bu W, Ji H, Zhao X, et al. (2013) Differential regulation of c-Jun protein plays an instrumental role in chemoresistance of cancer cells. J Bio Chem 288: 19321-19329.

33. Meng $\mathrm{H}$, Liong M, Xia T, Li Z, Ji Z, et al. (2010) Engineered design of mesoporous silica nanoparticles to deliver doxorubicin and P-glycoprotein siRNA to overcome drug resistance in a cancer cell line. ACS Nano 4: 45394550 .

34. Meng H, Mai WX, Zhang H, Xue M, Xia T, et al. (2013) Codelivery of an optima drug/siRNA combination using mesoporous silica nanoparticles to overcome drug resistance in breast cancer in vitro and in vivo. ACS Nano 7: 994-1005.

35. Chen AM, Zhang M, Wei D, Stueber D, Taratula O, et al. (2009) Co-delivery of doxorubicin and $\mathrm{Bcl}-2$ siRNA by mesoporous silica nanoparticles enhances the efficacy of chemotherapy in multidrug-resistant cancer cells. Small 5: 2673 2677. 
Citation: Zhao N, Woodle MC, Mixson AJ (2018) Advances in Delivery Systems for Doxorubicin. J Nanomed Nanotechnol 9: 519. doi: 10.4172/21577439.1000519

36. Liu Z, Balasubramanian V, Bhat C, Vahermo M, Makila E, et al. (2017) Quercetin-Based Modified Porous Silicon Nanoparticles for Enhanced Inhibition of Doxorubicin-Resistant Cancer Cells. Adv Healthc Mater.

37. Trouet A, Deprez-de Campeneere D, De Duve C (1972) Chemotherapy through Iysosomes with a DNA-daunorubicin complex. Nat New Biol 239: 110-112.

38. Trouet A, Deprez-de Campeneere D, de Smedt-Malengreaux M, Atassi G (1974) Experimental leukemia chemotherapy with a "lysosomotropic" adriamycin-DNA complex. Eur J Cancer 10: 405-411.

39. Leng Q, Chou ST, Scaria PV, Woodle MC, Mixson AJ (2014) Increased tumo distribution and expression of histidine-rich plasmid polyplexes. J Gene Med 16: $317-328$

40. Leng Q, Mixson AJ (2016) The neuropilin-1 receptor mediates enhanced tumor delivery of H2K polyplexes. J Gene Med 18: 134-144.

41. Leng Q, Scaria P, loffe OB, Woodle M, Mixson AJ (2006) A branched histidine/ lysine peptide, $\mathrm{H} 2 \mathrm{~K} 4 \mathrm{~b}$, in complex with plasmids encoding antitumor proteins inhibits tumor xenografts. J Gene Med 8: 1407-1415.

42. Manfait M, Alix AJ, Jeannesson P, Jardillier JC, Theophanides T (1982) Interaction of adriamycin with DNA as studied by resonance Raman spectroscopy. Nucleic Acids Res 10: 3803-3816.

43. Chaires JB, Fox KR, Herrera JE, Britt M (1987) Site and sequence specificity of the daunomycin-DNA interaction. Biochemistry 26: 8227-8236.

44. Anderson RD, Veigl ML, Baxter J, Sedwick WD (1991) DNA sequence specificity of doxorubicin-induced mutational damage in uvrB- Escherichia coli. Cancer Res 51: 3930-3937.

45. Phillips DR, Greif PC, Boston RC (1988) Daunomycin-DNA dissociation kinetics. Mol Pharmacol 33: 225-230.

46. Skorobogaty A, White RJ, Phillips DR, Reiss JA (1988) The 5'-CA DNAsequence preference of daunomycin. FEBS Lett 227: 103-106.

47. Mizuno Y, Naoi T, Nishikawa M, Rattanakiat S, Hamaguchi N, et al. (2010) Simultaneous delivery of doxorubicin and immunostimulatory CpG motif to tumors using a plasmid DNA/doxorubicin complex in mice. J Control Release 141: 252-259.

48. Charbgoo F, Alibolandi M, Taghdisi SM, Abnous K, Soltani F, et al. (2018) MUC1 aptamer-targeted DNA micelles for dual tumor therapy using doxorubicin and KLA peptide. Nanomedicine 14: 685-697.

49. Bagalkot V, Farokhzad OC, Langer R, Jon S (2006) An aptamer-doxorubicin physical conjugate as a novel targeted drug-delivery platform. Angew Chem Int Ed Engl 45: 8149-8152.

50. Tan L, Neoh KG, Kang ET, Choe WS, Su X. (2011) PEGylated anti-MUC1 aptamer-doxorubicin complex for targeted drug delivery to MCF7 breast cancer cells. Macromol Biosci 11: 1331-1335.

51. Wang Y, Chen J, Liang X, Han H, Wang H, et al. (2017) An ATP-Responsive Codelivery System of Doxorubicin and MiR-34a To Synergistically Inhibit Cell Proliferation and Migration. Mol Pharm 14: 2323-2332.
52. Zhang P, Ye J, Liu E, Sun L, Zhang J, et al. (2017) Aptamer-coded DNA nanoparticles for targeted doxorubicin delivery using $\mathrm{pH}$-sensitive spacer. Frontiers of Chem Sci and Eng 11: 529-536.

53. Nishikawa M, Mizuno Y, Mohri K, Matsuoka N, Rattanakiat S, et al. (2011) Biodegradable CpG DNA hydrogels for sustained delivery of doxorubicin and immunostimulatory signals in tumor-bearing mice. Biomaterials 32: 488-494.

54. Chen Y, Wu JJ, Huang L (2010) Nanoparticles targeted with NGR motif deliver c-myc siRNA and doxorubicin for anticancer therapy. Mol Ther 18: 828-834.

55. Leng Q, Woodle MC, Mixson AJ (2017) Targeted Delivery of siRNA Therapeutics to Malignant Tumors. J Drug Deliv 2017: 6971297.

56. Xia Z, Wang P, Liu X, Liu T, Yan Y, et al. (2016) Tumor-penetrating peptidemodified dna tetrahedron for targeting drug delivery. Biochemistry 55: 13261331.

57. Chun C, Lee SM, Kim CW, Hong KY, Kim SY, et al. (2009) Doxorubicinpolyphosphazene conjugate hydrogels for locally controlled delivery of cancer therapeutics. Biomaterials 30: 4752-4762.

58. Wu W, Chen H, Shan F, Zhou J, Sun X, et al. (2014) A novel doxorubicin-loaded in situ forming gel based high concentration of phospholipid for intratumoral drug delivery. Mol Pharm 11: 3378-3385.

59. Yuan Z, Pan Y, Cheng R, Sheng L, Wu W, et al. (2016) Doxorubicin-loaded mesoporous silica nanoparticle composite nanofibers for long-term adjustments of tumor apoptosis. Nanotechnology 27: 245101.

60. Cinar G, Ozdemir A, Hamsici S, Gunay G, Dana A, et al. (2016) Local delivery of doxorubicin through supramolecular peptide amphiphile nanofiber gels. Biomater Sci 5: 67-76.

61. Al-Abd AM, Hong KY, Song SC, Kuh HJ (2010) Pharmacokinetics of doxorubicin after intratumoral injection using a thermosensitive hydrogel in tumor-bearing mice. J Control Release 142: 101-107.

62. Kang YM, Kim GH, Kim JI, Kim DY, Lee BN, et al. (2011) In vivo efficacy of an intratumorally injected in situ-forming doxorubicin/poly(ethylene glycol)-bpolycaprolactone diblock copolymer. Biomaterials 32: 4556-4564.

63. Luo JW, Zhang T, Zhang Q, Cao X, Zeng X, et al. (2016) A novel injectable phospholipid gel co-loaded with doxorubicin and bromotetrandrine for resistant breast cancer treatment by intratumoral injection. Colloids Surf B Biointerfaces 140: 538-547.

64. Shen N, Hu J, Zhang L, Zhang L, Sun Y, et al. (2012) Doxorubicin-loaded zein in situ gel for interstitial chemotherapy of colorectal cancer. Acta Pharma Sinica B 2: 610-614.

65. Kim DY, Kwon DY, Kwon JS, ParkJH, Park SH, et al. (2016) Synergistic anti-tumor activity through combinational intratumoral injection of an in-situ injectable drug depot. Biomaterials 85: 232-245.

66. Zhang X, Teodoro JG, Nadeau JL (2015) Intratumoral gold-doxorubicin is effective in treating melanoma in mice. Nanomedicine 11: 1365-1375. 